\title{
The Impact of Labor Market Reforms on Capital Flows, Wages and Unemployment
}

\author{
Thomas Beissinger \\ University of Regensburg and IZA, Bonn
}

Discussion Paper No. 390

November 2001

\author{
IZA \\ P.O. Box 7240 \\ D-53072 Bonn \\ Germany \\ Tel.: +49-228-3894-0 \\ Fax: +49-228-3894-210 \\ Email: iza@iza.org
}

This Discussion Paper is issued within the framework of IZA's research area Internationalization of Labor Markets and European Integration. Any opinions expressed here are those of the author(s) and not those of the institute. Research disseminated by IZA may include views on policy, but the institute itself takes no institutional policy positions.

The Institute for the Study of Labor (IZA) in Bonn is a local and virtual international research center and a place of communication between science, politics and business. IZA is an independent, nonprofit limited liability company (Gesellschaft mit beschränkter Haftung) supported by the Deutsche Post AG. The center is associated with the University of Bonn and offers a stimulating research environment through its research networks, research support, and visitors and doctoral programs. IZA engages in (i) original and internationally competitive research in all fields of labor economics, (ii) development of policy concepts, and (iii) dissemination of research results and concepts to the interested public. The current research program deals with (1) mobility and flexibility of labor markets, (2) internationalization of labor markets and European integration, (3) the welfare state and labor markets, (4) labor markets in transition, (5) the future of work, (6) project evaluation and (7) general labor economics.

IZA Discussion Papers often represent preliminary work and are circulated to encourage discussion. Citation of such a paper should account for its provisional character. 


\section{ABSTRACT}

\section{The Impact of Labor Market Reforms on Capital Flows, Wages and Unemployment}

The paper contributes to the globalization debate by scrutinizing the international spillover effects which are provoked if a single country reduces the generosity of the unemployment compensation system or weakens labor union power. For this purpose a two-country model with mperfect competition in goods and labor markets and perfect competition in capital markets is developed. It is demonstrated that the comparative-static results depend on the degree of capital mobility, the degree of competition in the goods market and the institutional setup of the unemployment compensation system. Furthermore, it is shown that the impact of country-specific labor market reforms on households in other countries depends on whether the household's main income source consists of wage income or capital income and profits.

JEL Classification: E24, F21, F41, J23, J51, J65

Keywords: Globalization, capital mobility, unemployment, unemployment compensation, wage bargaining, monopolistic competition, welfare state

Thomas Beissinger

Department of Economics

University of Regensburg

93040 Regensburg

Germany

Tel.: +499419432740

Fax: +49 9419432735

Email: Thomas.beissinger@wiwi.uni-regensburg.de

\footnotetext{
* I thank Oliver Büsse, Josef Falkinger, Volker Großmann, Susanne Koch, Joachim Möller, Michael Plüger and Winfried Vogt for valuable comments and suggestions. The paper has also profited from comments made by participants at the 56th European Meeting of the Econometric Society in Lausanne, the annual congress of the Verein für Socialpolitik in Berlin and seminars at the Institute for Employment Research (IAB) in Nuremberg and the Institute for the Study of Labor (IZA) in Bonn.
} 


\section{Introduction}

Trade liberalization and deregulation of financial markets have led to highly integrated goods and capital markets during the last decades. These developments, frequently subsumed under the general heading "globalization", have initiated a lively debate among economists as well as the general public about the potential winners and losers of the increased openness of economies. One aspect of this debate, e.g. reflected in catchwords like "social dumping", focuses on the consequences of globalization on the welfare state and labor market institutions. It is feared that the domestic economy may be adversely affected by a dismantling of welfare states or deregulation of labor markets abroad (cf. Rodrik, 1997).

On theoretical grounds such fears are often backed up by models in which labor mobility plays a central role. ${ }^{1}$ If an economy with a generous welfare state attracts a huge number of immigrants from economies which have lowered public provisions, this may lead to higher unemployment and lower real wages as long as the domestic welfare state remains unchanged. Despite the plausibility of the theoretical argument, the empirical evidence points to a rather low labor mobility between countries, which seems to suggest that such fears are exaggerated (cf. Krueger, 2000). However, labor mobility is not necessary for competitive forces to exert pressure on uncompetitive labor market institutions. Even if the international mobility of labor were completely hindered by political measures, free flows of goods or capital could prove to be sufficient to put a strain on the welfare state.

The following analysis contributes to this discussion by scrutinizing the spillover effects on other countries which are provoked if a single country weakens labor union power or reduces the generosity of the unemployment compensation system. By this, the paper takes up Pemberton's (1999) claim that social security policies must be analyzed in an open-economy context since international spillovers have to be taken into account. In the two-country framework developed in this paper spillover effects may occur because goods and capital markets are internationally integrated. The model assumes that international

\footnotetext{
${ }^{1}$ See, for instance, the discussion in Sinn (1998).
} 
mobility of labor is completely hindered by cultural and linguistic barriers. National labor markets are characterized by country-specific labor market institutions which influence the result of wage bargains taking place between firms and labor unions. It is assumed that one country undertakes labor market reforms which are aimed at increasing employment in that country. The reforms may, for instance, consist of the reduction of unemployment benefits or the modification of labor market legislation to reduce labor union power in wage negotiations. In the globalization debate it is feared that such reforms may be harmful for other countries. This paper deals with the question whether and under which conditions these fears are justified. It will be shown that the impact of country-specific labor market reforms on households in other countries depends on whether the household's main income source consists of wage income or capital income and profits.

It is sometimes objected that the integration of goods and capital markets, if viewed in historical perspective, is not a new phenomenon but was already a characteristic feature of economies before World War I. Some economists are therefore inclined to downplay the role of globalization for the shape of the welfare state. However, such a conclusion seems to be premature. In the early twentieth century welfare states, as we know them today, were nonexistent. Conversely, when modern welfare states came into being, economies were relatively closed - especially with respect to capital flows (cf. Obstfeld, 1998). Hence, for instance, Mishra (1999) argues that from the standpoint of the welfare state the openness of economies with respect to capital mobility is an entirely new and important development which could lead to a dismantling of social security provisions. To scrutinize whether such a hypothesis can be backed up by theoretical considerations, the paper adopts the following strategy. Throughout the paper it is assumed that goods markets are integrated. The impact of country-specific labor market reforms on other countries is then first analyzed for a world with immobile capital, before perfect capital mobility is introduced.

An important hypothesis of the following analysis will be that spillover effects of country-specific labor market reforms also depend on the degree of competition in the goods market. To examine this hypothesis, a model with monopolistic competition in the goods market is chosen, where varying degrees of competition are represented by different 
sizes of the elasticity of the demand for goods. If the demand elasticity is infinite, the model reduces to the limiting case with perfect competition in the goods market.

The analysis also carries on previous work dealing with the impact of the unemployment compensation system on international spillover effects. ${ }^{2}$ By this, the paper contributes to a branch of the literature which emerged in reaction to Atkinson, Micklewright (1991), who complained about theoretical studies which have largely ignored real-world differences in unemployment compensation systems. In most economies unemployment compensation is usually implemented as a two-tier system comprising earningsrelated unemployment benefits and flat-rate unemployment assistance. In the model presented below the focus is on the extreme cases where unemployment compensation in a country is either earnings-related or paid as flat-rate transfers. This makes it clearer how institutional differences influence comparative-static outcomes and nevertheless leads to important insights for real-world unemployment compensation systems. The German and UK systems of unemployment compensation most closely resemble the considered (extreme) cases, since in Germany both unemployment benefits and unemployment assistance are earnings-related, whereas in the UK both are paid as flat-rate transfers. Up to now, all these aspects of country-specific labor market reforms have not simultaneously been discussed in a single model. ${ }^{3}$

The remainder of the paper is organized as follows. In section 2 the theoretical framework for a two-country model with imperfectly competitive labor and product markets is introduced. In section 3 the comparative-static results for a world with immobile capital

\footnotetext{
${ }^{2}$ See Beissinger and Büsse $(2000,2001)$. In these papers only a theoretical framework with immobile capital has been considered. Furthermore, the dependence of the results on the degree of competition in the goods market as well as the distributional consequences of labor market reforms have not been taken into account.

${ }^{3} \mathrm{~A}$ two-country model with perfect competition in the goods market and wage bargaining in the labor market is analyzed by Lejour, Verbon (1996). In that paper the results (also) depend on their assumption of perfect competition in the goods market. Other studies with integrated goods markets and separated labor markets are Corneo (1995) and Naylor (1998). However, these authors do not take account of capital flows. They also restrict their analysis to a small, single industry located in both countries and hence do not consider the macroeconomic consequences of changing wage pressure in one country, which for instance are due to changing aggregate income.
} 
are presented. In section 4 it is analyzed how the results change if capital is perfectly mobile and the induced capital flows are taken into account. In both sections the simpler case with perfect competition in the goods market is discussed first, before the more general model based on monopolistic competition is examined. It is shown that the qualitative results in all cases considered depend on whether the unemployment compensation system is based on earnings-related or flat-rate benefits. Furthermore, in both sections the consequences for households with different income sources are discussed. Section 5 contains the concluding remarks.

\section{The theoretical framework}

In the two-country model developed in this paper it is assumed that all goods are tradable, i.e. the nontraded goods sector is neglected. The model is intended to be a description of the longer run, where expectations are correct and nominal rigidities play no role. The outcome of the wage-setting process is influenced by the relative bargaining power of firms and unions, the preferences of labor unions for employment and wages and the institutional setup of the social security system. It is assumed that countries are different with respect to these variables, but are identical otherwise. The differences in wage setting may lead to country-specific wage and price levels which can persist since migration of the labor force is impeded by cultural and linguistic barriers. Beside the number of households also the number of firms in both countries is exogenously given, which may be due to barriers to market entry provoked by sunk costs. Some households are owners of the firms, for instance because they own the blueprints for producing a certain brand. ${ }^{4}$ These households obtain the profits of the firms for their managerial activities. For production labor and (physical) capital is needed, which is supplied by the same or by other households. The role of the government is restricted to the provision of unemployment benefits financed by a proportional tax on wage income.

\footnotetext{
${ }^{4}$ Hence, the firms in a country are in the possession of domestic residents.
} 


\subsection{Demand for goods}

It is assumed that in each country $\mathrm{A}$ and $\mathrm{B}$ there are $F / 2$ firms and $L$ consumers/workers. Consumer preferences are identical and comprise all goods produced in this two-country world. Consumers in country $h$ have the following Dixit, Stiglitz (1977) type utility function: ${ }^{5}$

$$
U^{h}=F^{\frac{\kappa-1}{\kappa}}\left(\sum_{i=1}^{F / 2}\left(Y_{i A}^{h}\right)^{\kappa}+\sum_{i=1}^{F / 2}\left(Y_{i B}^{h}\right)^{\kappa}\right)^{\frac{1}{\kappa}}, \quad 0<\kappa \leq 1, \quad h=A, B,
$$

where $\kappa \equiv(\eta-1) / \eta$ and $\eta>1 . Y_{i j}^{h}$ denotes the quantity of good $i$ produced in country $j=$ $A, B$ which is purchased by a consumer located in country $h=A, B$. It is assumed that each consumer inelastically supplies one unit of labor in the respective home country. Consumers are also endowed with capital and own the firms of the domestic economy. The (exogenous) distribution of capital and property rights varies across consumers. Hence, there are consumers whose income primarily stems from wages and others for whom capital income and profits are the main income sources. However, since the utility function in eq. (1) is homothetic, the distribution of income plays no role for the demand function of firms. The nominal income $I^{h}$ of a consumer in country $h$ comprises capital income, profits and wage income or unemployment benefits. Customs duties, value added taxes and transportation costs are neglected in the model. This implies that the price $P_{i j}$ for a specific good is the same for consumers and producers of either country. A consumer of country $h$ faces the budget constraint

$$
\sum_{i=1}^{F / 2} P_{i A} Y_{i A}^{h}+\sum_{i=1}^{F / 2} P_{i B} Y_{i B}^{h}=I^{h}, \quad h=A, B .
$$

Corresponding to the utility function in eq. (1) the aggregate price index $P$ is defined as

$$
P=F^{\frac{1}{\eta-1}}\left(\sum_{i=1}^{F / 2} P_{i A}^{1-\eta}+\sum_{i=1}^{F / 2} P_{i B}^{1-\eta}\right)^{\frac{1}{1-\eta}} .
$$

By maximizing eq. (1) with respect to $Y_{i j}^{h}$ and taking account of eqs. (2) and (3), the demand functions of each consumer can be derived. To obtain the demand function for

\footnotetext{
${ }^{5}$ To simplify the notation, the index for consumers is omitted.
} 
the producer of good $i$ in country $j$, one has to sum up the demand functions of the consumers of both countries for the respective good. Defining world real income $Y$ as the sum of country-specific real income levels (in terms of the aggregate good), demand for good $Y_{i j}$ is given by the Blanchard, Kiyotaki (1987) type function

$$
Y_{i j}^{d}=p_{i j}^{-\eta} \frac{Y}{F}, \quad i=1, \ldots, F / 2, \quad j=A, B
$$

In this equation $p_{i j}$ denotes relative prices in terms of the aggregate good, i.e. $p_{i j} \equiv P_{i j} / P$. The elasticity of the demand for goods is constant and equals $\eta$ (in absolute values). Of course, in general equilibrium world real income $Y$ is itself an endogenous variable, but from the firm's point of view it is taken as exogenous since it is assumed that there are a large number of firms in the two-country world. Note that the parameter $\kappa \equiv(\eta-1) / \eta$ is a function of the demand elasticity and can be interpreted as a measure of the degree of competition in the goods market. With perfect competition the demand elasticity is infinite and therefore $\kappa=1$. With monopolistic competition in the goods market $\kappa<1$, with $\kappa$ becoming lower when the demand elasticity is decreasing. In the following analysis $\kappa$ will play an important role in distinguishing model variants with different degrees of competition in the goods market.

In equilibrium demand equals supply. Furthermore, all firms belonging to the same country are facing the same (country-specific) wage rate and the same real interest rate. Firms also share the same technology. As a result, firms in country $j$ choose the same (relative) price, i.e. $p_{i j}=p_{j}$, and produce the same quantity. It therefore holds that $Y_{j}=(F / 2) Y_{i j}$, where $Y_{j}$ denotes production in country $j$. This leads to the following inverse demand function for country $j$ :

$$
p_{j}=\left(\frac{Y}{2 Y_{j}}\right)^{1-\kappa}, \quad j=A, B .
$$

Written in relative changes, this equation becomes

$$
\widehat{p}_{j}=(1-\kappa)\left(\widehat{Y}-\widehat{Y}_{j}\right), \quad j=A, B
$$

where a hat over a variable denotes relative changes. 


\subsection{Demand for labor and capital}

Producers act as monopolistic competitors, taking account of the product demand function (4) when choosing factor demands. It is assumed that the single firm is small compared to the economy as a whole. As a result, each firm does not need to consider the consequences of its actions for the aggregate variables and for the other firms. For the determination of factor demands the following sequence of events is assumed in line with the literature ${ }^{6}$. First, firms choose the stock of capital. Then wages are determined in firm-level wage bargains. As the last step firms choose the optimal employment level given the predetermined capital stock and wages.

Firms use the Cobb-Douglas technology $Y_{i j}=N_{i j}^{\alpha} K_{i j}^{1-\alpha}$, where $N_{i j}$ is employment and $K_{i j}$ is the stock of capital of firm $i$ in country $j=A, B$. Taking account of eq. (4), revenue $R_{i j}$ in terms of the aggregate good is $R_{i j}=p_{i j} Y_{i j}=Y_{i j}^{\kappa}(Y / F)^{1-\kappa}$. Each firm chooses the employment level according to the condition $\partial R_{i j} / \partial N_{i j}=w_{i j}$, where $w_{i j}$ is the real wage in terms of the aggregate good. Marginal revenue with respect to employment is

$$
\frac{\partial R_{i j}}{\partial N_{i j}}=\kappa p_{i j} \frac{\partial Y_{i j}}{\partial N_{i j}}=\kappa\left[Y_{i j}^{\kappa-1}\left(\frac{Y}{F}\right)^{1-\kappa}\right] \frac{\partial Y_{i j}}{\partial N_{i j}} .
$$

If the Cobb Douglas production function is inserted in this equation, the first order condition for maximum profits leads to the following labor demand functions:

$$
N_{i j}=\left\{w_{i j}^{-1} \alpha \kappa K_{i j}^{(1-\alpha) \kappa}\left(\frac{Y}{F}\right)^{1-\kappa}\right\}^{\frac{1}{1-\alpha \kappa}}, \quad i=1, \ldots, F / 2, \quad j=A, B .
$$

When firms determine the capital stock on the first stage they take account of the wage level that will result on the second stage. Denoting the real interest rate in terms of the aggregate good as $r_{j}$, firms choose the stock of capital according to $\partial R_{i j} / \partial K_{i j}=$ $r_{j}+N_{i j} \partial w_{i j} / \partial K_{i j}$, since the bargained real wage, in general, depends on the level of the capital stock. ${ }^{7}$ However, in the case of a Cobb-Douglas production function it holds that

\footnotetext{
${ }^{6}$ See, for instance, Hoel (1990) and Michaelis (1998). Grout (1984) discusses the consequences of this assumption compared to the case where unions can commit themselves to a wage rate before investments are determined. See also the discussion in van der Ploeg (1987).

${ }^{7}$ Without capital mobility the real interest rate may differ between countries, whereas in the case with perfect capital mobility it must be the same.
} 
$\partial w_{i j} / \partial K_{i j}=0$, as will be shown in a moment. The demand for capital is then given by

$$
K_{i j}=\left\{r_{j}^{-1}(1-\alpha) \kappa N_{i j}^{\alpha \kappa}\left(\frac{Y}{F}\right)^{1-\kappa}\right\}^{\frac{1}{1-(1-\alpha) \kappa}}, \quad i=1, \ldots, F / 2, \quad j=A, B .
$$

The fact that marginal revenue with respect to factor inputs is a function of world real income is of uttermost importance for the results of this paper. All other things being constant, an increase in aggregate income $Y$ leads to a rise in the relative price $p_{i j}$ and hence to a rise of marginal revenue. As a consequence, firms increase factor inputs which reduces the marginal product and $p_{i j}$ until the first order condition for a profit maximum is restored. In the following the impact of aggregate income on marginal revenue and hence factor inputs will be called the aggregate income effect. With perfect competition in the goods market $\kappa=1$ and therefore $p_{i j}=1$, which implies that there is no aggregate income effect. For the comparative-static analysis it is also important to take the consequences of different levels of $\kappa$ into account if monopolistic competition prevails in the goods market (i.e. $\kappa<1$ ). As is evident from the factor demand functions, a higher $\kappa$ reduces the aggregate income effect. At the same time the elasticities with respect to the respective factor price (in absolute values) and the other factor input increase.

It is assumed that all firms and labor unions of the respective country are identical, hence $p_{i j}=p_{j}$ and $w_{i j}=w_{j}$ must hold in equilibrium. It follows that $N_{j}=(F / 2) N_{i j}$, $K_{j}=(F / 2) K_{i j}$ and $Y_{j}=(F / 2) Y_{i j}$, where $N_{j}, K_{j}$ and $Y_{j}$ denote the national levels of employment, the stock of capital and output, respectively. The production function for each country (in relative changes) is therefore given by

$$
\widehat{Y}_{j}=\alpha \widehat{N}_{j}+(1-\alpha) \widehat{K}_{j}, \quad j=A, B
$$

From eqs. (7) and (8) the relative change in the demand for labor and capital for every country can be derived as

$$
\widehat{N}_{j}=-\frac{1}{1-\psi_{N}} \widehat{w}_{j}+\frac{\psi_{K}}{1-\psi_{N}} \widehat{K}_{j}+\frac{1-\kappa}{1-\psi_{N}} \widehat{Y}, \quad j=A, B
$$

and

$$
\widehat{K}_{j}=-\frac{1}{1-\psi_{K}} \widehat{r}_{j}+\frac{\psi_{N}}{1-\psi_{K}} \widehat{N}_{j}+\frac{1-\kappa}{1-\psi_{K}} \widehat{Y}, \quad j=A, B
$$


where $\psi_{N} \equiv \alpha \kappa$ and $\psi_{K} \equiv(1-\alpha) \kappa$ denote the shares of labor and capital income in national output. Employment can be substituted by unemployment, since $N_{j}=\left(1-u_{j}\right) L$, where $L$ is the (exogenously given) labor supply in every country. Hence,

$$
\widehat{N}_{j}=-\left(1 / \beta_{j}\right) \widehat{u}_{j}, \quad \beta_{j} \equiv\left(1-u_{j}\right) / u_{j}>0, \quad j=A, B .
$$

\subsection{Country-specific wage setting}

It is assumed that in every country wage bargains take place at the firm level. For the utility function $V_{i j}$ of labor union $i$ in country $j$ the following functional form is used:

$$
V_{i j}=N_{i j}^{\phi_{j}}\left[w_{i j}\left(1-t_{j}\right)-z_{j}\right], \quad \phi_{j}>0, \quad \forall i, j,
$$

where $\phi_{j}$ represents unions' preferences for employment relative to wages and $t_{j}$ denotes the tax rate on wage income, $j=A, B$. The variable $z_{j}$ is the expected real income of a worker in country $j$ who loses his job in the firm under consideration. ${ }^{8}$ As the bargaining parties are small units compared to the whole (national) economy, $z_{j}$ is exogenous for the single firm or union. The real wage in terms of the aggregate good $w_{i j}$ is obtained as solution of a Nash bargain with zero fall-back positions for unions and firms, $V_{i j}^{\chi_{j}} \Pi_{i j}^{1-\chi_{j}}$, where $0<\chi_{j}<1$. The parameter $\chi_{j}$ denotes the bargaining power of a representative union in country $j$ and $\Pi_{i j}$ the (real) profits of the respective firm. After some rearrangement, the first-order condition for this optimization problem can be written as

$$
w_{i j}\left(1-t_{j}\right)=\frac{\mu_{j}}{\mu_{j}-1} z_{j}, \quad \text { with } \quad \mu_{j}=\mu_{j}\left(\phi_{j}, \chi_{j}\right) \equiv \frac{\phi_{j}+\frac{1-\chi_{j}}{\chi_{j}} \alpha \kappa}{1-\alpha \kappa} .
$$

The bargained real wage at the firm level is a mark-up on the expected alternative income $z_{j}$, where the mark-up is a negative function of $\mu_{j}$. In order to get a permissible solution for $w_{i j}$ it must hold that $\mu_{j}>1$. It is evident from eq. (14) that $\mu_{j}$ is constant, which is due to the assumption of a Cobb-Douglas technology. As a result, the bargained real wage is independent of the chosen stock of capital, i.e. $\partial w_{i j} / \partial K_{i j}=0$. As underlying causes of a variation in $\mu_{j}$ only changes in $\phi_{j}$ and $\chi_{j}$ are considered. From the definition of $\mu_{j}$ in eq. (14) follows:

$$
\widehat{\mu}_{j}=\frac{\phi_{j}}{(1-\alpha \kappa) \mu_{j}} \widehat{\phi}_{j}-\frac{1}{\chi_{j} \mu_{j}} \widehat{\chi}_{j} .
$$

\footnotetext{
${ }^{8}$ For similar specifications see, for example, Oswald (1985) and Manning (1991, 1995).
} 
Since migration is excluded, the expected alternative income $z_{j}$ depends solely on variables specific to country $j$ :

$$
z_{j}=\left(1-u_{j}\right) w_{j}\left(1-t_{j}\right)+u_{j} s_{j}
$$

where $w_{j}$ is the average wage level and $s_{j}$ is the real unemployment compensation in country $j$ (both in terms of the aggregate good). The probability of finding a job elsewhere in that country negatively depends on the respective unemployment rate $u_{j}$. In general, unemployment benefits may consist of a flat-rate component and a component related to earnings, i.e.

$$
s_{j}=\gamma_{j} \rho_{j} w_{j}\left(1-t_{j}\right)+\left(1-\gamma_{j}\right) b_{j} \quad 0 \leq \gamma_{j} \leq 1, \quad 0<\rho_{j}<1, \quad b_{j}>0,
$$

where $\gamma_{j}$ denotes the share of earnings-related benefits in total unemployment compensation. The parameter $\rho_{j}$ reflects the ratio of benefits to wages in the earnings-related component and $b_{j}$ denotes flat-rate unemployment benefits (in real terms). It is assumed that earnings-related benefits are a function of after-tax wages. This corresponds, for instance, to the German system of unemployment compensation. ${ }^{9}$

In equilibrium it must hold that $w_{i j}=w_{j}$. Using the definitions of $z_{j}$ and $s_{j}$ together with the firm-level wage equation (14), the national wage-setting equation is

$$
w_{j}\left(\frac{\mu_{j} u_{j}\left(1-\gamma_{j} \rho_{j}\right)-1}{\mu_{j} u_{j}}\right)=\left(1-\gamma_{j}\right) \frac{b_{j}}{1-t_{j}} .
$$

In the following the focus is on the extreme cases where unemployment compensation is either earnings-related $\left(\gamma_{j}=1\right)$ or paid as flat-rate transfers $\left(\gamma_{j}=0\right)$. This makes it clearer how institutional differences influence comparative-static outcomes and nevertheless leads to important insights for real world unemployment compensation systems. If $\gamma_{j}=1$ the wage-setting equation alone already determines the level of unemployment. The reason is that in this case the expression in parentheses on the left-hand side, which contains only the unemployment rate as endogenous variable, must be zero. However, if $\gamma_{j}=0$ both

\footnotetext{
${ }^{9}$ In accordance with the literature, in eq. (17) it is assumed that earnings-related benefits are a function of the average wage level in the respective country. This guarantees that $z_{j}$ is exogenous in the firm level bargain. Beissinger and Egger (2000) discuss within a dynamic wage bargaining model the complications which arise if this assumption is abandoned.
} 
the unemployment rate and the real wage show up as endogenous variables in the wagesetting equation. Before writing the wage-setting equations in relative changes, first the implications of the government budget constraint on the wage-setting process are taken into account.

\subsection{Implications of the government budget constraint for the bar- gained real wage}

Tax revenues are solely used to finance unemployment benefits. In this case the government budget $\mathrm{GB}_{j}$ is given by $\mathrm{GB}_{j}=t_{j} w_{j} N_{j}-\left(L-N_{j}\right) s_{j}$. Taking account of the definition of $s_{j}$ in eq. (17) the government budget is balanced if

$$
t_{j}=\left\{\begin{array}{rlr}
u_{j} \rho_{j} /\left(1-u_{j}\left(1-\rho_{j}\right)\right) & \text { for } & \gamma=1 \\
u_{j} b_{j} /\left(w_{j}\left(1-u_{j}\right)\right) & \text { for } & \gamma=0
\end{array}\right.
$$

In the earnings-related unemployment compensation system $\left(\gamma_{j}=1\right)$ the outcome of the wage bargain does not depend on the level of income taxes. This is due to the fact that unemployment benefits are a constant fraction of after-tax wages. Hence the wage-setting equation (18) in relative changes is

$$
\widehat{u}_{j}=\Omega_{j}, \quad \text { with } \quad \Omega_{j} \equiv-\widehat{\mu}_{j}+\frac{\rho_{j}}{1-\rho_{j}} \widehat{\rho}_{j} .
$$

With flat-rate benefits $\left(\gamma_{j}=0\right)$, one must take account of eq. (19) in the wage-setting equation (18). Writing the resulting expression in relative changes leads to

$$
\widehat{w}_{j}=-\nu_{j} \widehat{u}_{j}+\widetilde{\Omega}_{j} \text { with } \nu_{j} \equiv \frac{1-\mu_{j} u_{j}^{2}}{\left(\mu_{j} u_{j}-1\right)\left(1-u_{j}\right)}, \widetilde{\Omega}_{j} \equiv \frac{-\left(1-u_{j}\right) \mu_{j} \widehat{\mu}_{j}}{\left(\mu_{j} u_{j}-1\right)\left(\mu_{j}-1\right)}+\widehat{b}_{j} .
$$

Higher unemployment implies higher payroll taxes which cet. par. leads to higher wage pressure. To guarantee the empirically confirmed result that higher unemployment leads to lower wages, it must be assumed that $\mu_{j} u_{j}>1$ and $\mu_{j} u_{j}^{2}<1$. Hence, higher unem-

ployment only lowers the bargained real wage if $\mu_{j}^{-1}<u_{j}<\mu_{j}^{-1 / 2}$. In the following it is assumed that this condition holds, which implies $\nu_{j}>0$.

The change in the tax rate, which is necessary for balancing the government budget, can be computed from eq. (19). With an earnings-related unemployment compensation 
system one gets

$$
\widehat{t}_{j}=\frac{1}{1-u_{j}\left(1-\rho_{j}\right)} \widehat{u}_{j}+\frac{1-u_{j}}{1-u_{j}\left(1-\rho_{j}\right)} \widehat{\rho}_{j}, \quad j=A, B
$$

and with flat-rate benefits:

$$
\widehat{t}_{j}=\frac{1}{1-u_{j}} \widehat{u}_{j}+\widehat{b}_{j}-\widehat{w}_{j}, \quad j=A, B
$$

\subsection{Capital market equilibrium and aggregate output}

If capital is immobile, the real interest rate $r_{j}$ (in terms of the aggregate good) equilibrates capital demand and supply in each country. However, if capital is (perfectly) mobile, the real interest rate must be the same in both countries. In the latter case the real interest rate $r$ equilibrates total world supply of capital $K$ with total capital demand, so $K_{A}+K_{B}=K$. Since it is assumed that the supply of capital is fixed, it must hold that

$$
\widehat{K}_{A}=-\left(K_{B} / K_{A}\right) \widehat{K}_{B}
$$

Turning to aggregate output which is equal to world real income, it has already been pointed out that $Y$ is a function of national output levels. Since national prices $P_{j}$ and hence also relative prices $p_{j} \equiv P_{j} / P, j=A, B$, may differ, aggregate output has to be written as $Y=p_{A} Y_{A}+p_{B} Y_{B}$. With the inverse demand functions (5) and the national Cobb-Douglas production functions one obtains as the relative change of aggregate output:

$$
\widehat{Y}=\alpha \delta \widehat{N}_{A}+\alpha(1-\delta) \widehat{N}_{B}+(1-\alpha) \delta \widehat{K}_{A}+(1-\alpha)(1-\delta) \widehat{K}_{B}
$$

where $\delta \equiv\left(p_{A} Y_{A}\right) /\left(p_{A} Y_{A}+p_{B} Y_{B}\right)$ denotes the share of country A's output in world output and $0<\delta<1$.

\subsection{The aim of the comparative-static analysis}

For the comparative-static analysis it is assumed that in country A labor market reforms are undertaken which are aimed at increasing employment in that country. In the model the following changes in country A are considered: 


\section{Assumption 1 (Labor market reforms in country A)}

In country A labor market reforms are undertaken which lead to one or several of the following consequences: i) a decrease in labor union power, $\chi_{A}$, ii) "corporatist behavior" of labor unions, which is modelled as an increase in labor unions' preferences for employment, $\phi_{A}$, iii) a reduction of unemployment benefits, i.e. a decrease in $\rho_{A}$ (or $\left.b_{A}\right)$. All types of labor market reforms lead to $\Omega_{A}<0$ (or $\widetilde{\Omega}_{A}<0$ ) in the wage-setting equation of country $A$, whereas it is assumed that $\Omega_{B}=0$ (and $\widetilde{\Omega}_{B}=0$ ) in the wage-setting equation of country $B$.

The focus of the analysis is on the spillover effects which country A might exert on country B due to the domestic labor market reforms. Note that it suffices to analyze the consequences of a reduction of $\Omega_{A}$ (or $\left.\widetilde{\Omega}_{A}\right)$ on the endogenous variables of the model, $\widehat{Y}, \widehat{r}, \widehat{w}_{j}, \widehat{p}_{j}, \widehat{t}_{j}, \widehat{Y}_{j}, \widehat{N}_{j}, \widehat{K}_{j}, \widehat{u}_{j}, j=A, B$. In order to simplify the comparative-static analysis, additionally the following assumption is made: ${ }^{10}$

\section{Assumption 2 (Symmetric initial equilibrium)}

In the initial equilibrium real wages, the stock of capital, employment and hence also unemployment rates and production levels are equal in both countries.

For Assumption 2 to make sense it is assumed that in the initial equilibrium in both countries the exogenous variables $\chi_{j}, \phi_{j}, \rho_{j}$ and $b_{j}$ are of the same size, respectively. Furthermore, it is assumed that in both countries always the same unemployment compensation system with either earnings-related benefits (ERB) or flat-rate benefits (FRB) prevails. The main consequences of Assumption 2 are summarized in

\footnotetext{
${ }^{10}$ It must be stressed that the qualitative results derived in this paper do not depend on this simplifying assumption. In fact, in a previous version of the paper the comparative-static analysis has been performed without making this assumption.
} 
Lemma 1 Assumption 2 implies that

$$
\begin{aligned}
\beta_{A} & =\beta_{B}=\beta \quad \text { in eq. (12) and } \nu_{A}=\nu_{B}=\nu \quad \text { in eq. (21), } \\
\widehat{K}_{A} & =-\widehat{K}_{B}, \\
\widehat{Y} & =\frac{\alpha}{2}\left(\widehat{N}_{A}+\widehat{N}_{B}\right), \\
\text { ERB: } \quad \widehat{t}_{j} & =\frac{1}{1-u(1-\rho)} \widehat{u}_{j}+\frac{1-u}{1-u(1-\rho)} \widehat{\rho}_{j}, \quad j=A, B \\
\text { FRB }: \quad \widehat{t}_{j} & =\frac{1}{1-u} \widehat{u}_{j}+\widehat{b}_{j}-\widehat{w}_{j}, \quad j=A, B .
\end{aligned}
$$

According to Lemma 1 relative changes in aggregate output are only due to relative changes in national employment levels, which follows from eq. (25) with $\delta=1 / 2$ and eq. $\left(24^{\prime}\right)$. Taking account of eq. (12), the wage-setting equations can be written in terms of employment instead of unemployment. This leads to:

$$
\begin{array}{lll}
\text { ERB: } & \widehat{N}_{A}=-\Omega_{A} / \beta & \widehat{N}_{B}=0 \quad \text { and } \\
\text { FRB: } & \widehat{w}_{A}=\nu \beta \widehat{N}_{A}+\widetilde{\Omega}_{A} & \widehat{w}_{B}=\nu \beta \widehat{N}_{B} .
\end{array}
$$

\section{Results with immobile capital as benchmark case}

In this section the consequences of country-specific labor market reforms are considered for a world with immobile capital. This facilitates the understanding of the model's implications and approximately describes the situation after World War II when modern welfare states came into being. With immobile capital it holds that $\widehat{K}_{A}=\widehat{K}_{B}=0$, i.e. the stock of capital is fixed in every country. If eq. $\left(25^{\prime}\right)$ for aggregate output is inserted in the labor demand equations (10), it becomes evident that labor demand of every country is influenced by the employment level of the other country. The labor demand equations can be solved for real wages, which leads to the following inverse labor demand equations: ${ }^{11}$

$$
\widehat{w}_{A}=-\left(\omega_{1}-\omega_{2}\right) \widehat{N}_{A}+\omega_{2} \widehat{N}_{B} \quad \text { and } \quad \widehat{w}_{B}=-\left(\omega_{1}-\omega_{2}\right) \widehat{N}_{B}+\omega_{2} \widehat{N}_{A},
$$

\footnotetext{
${ }^{11}$ In this form the labor demand equations can also be interpreted as the price-setting equations of each country, which denote the real wage the firms are willing to pay (cf. Layard et al. (1991)).
} 
where $\omega_{1} \equiv(1-\alpha \kappa), \omega_{2} \equiv(1-\kappa) \alpha / 2$, and $0<\omega_{i}<1$. Note that with $0<\kappa \leq 1$ and $0<\alpha<1$ it holds that $0<\left(\omega_{1}-\omega_{2}\right)<1$. As a result, the inverse labor demand curves described by eq. (26) are falling in $\widehat{w}_{j}-\widehat{N}_{j}$-space $(j=A, B)$.

In the following, the results with perfect competition in the goods market are presented first, before going over to the more general model with monopolistic competition.

\subsection{Perfect competition in the goods market}

Perfect competition in the goods market implies that $\kappa=1$. In this case the same homogenous good is produced in both countries. ${ }^{12}$ Since labor and capital are immobile, a trivial model is obtained where both countries in principle are closed economies and consumers of each country are exactly consuming the produced output of their own country. This leads to

\section{Proposition 1}

With perfect competition in the goods market and factor immobility, country $B$ is not affected by the labor-market reforms in country $A$, i.e. $\widehat{N}_{B}=0$ and $\widehat{w}_{B}=0$. In country $A$ real wages decline and employment increases, i.e. $\widehat{w}_{A}<0$ and $\widehat{N}_{A}>0$. These results hold irrespective of the unemployment compensation system.

Proof. Setting $\kappa=1$ implies $\omega_{2}=0$ in the labor demand equation (26) of each country. Combining this equation with the respective wage-setting equation $\left(20^{\prime}\right)$ or $\left(21^{\prime}\right)$ immediately leads to Proposition 1 , since $\Omega_{A}<0$ and $\widetilde{\Omega}_{A}<0$.

\subsection{Monopolistic competition in the goods market}

With monopolistic competition in the goods market different goods are produced in each country. It will become evident that in a world with immobile capital two effects are relevant for country B. Due to the labor market reforms in country A relative prices of that country will decline which is unfavorable for country B. However, world real income will rise which leads to an increase in labor demand in country B. In the following it must

\footnotetext{
${ }^{12}$ With $\kappa=1$ all goods are perfect substitutes (see eq. (1)), hence from the viewpoint of the consumer the goods are homogenous.
} 
be scrutinized whether the aggregate income effect or the relative price effect dominates. The consequences for country B also depend on the unemployment compensation system in that country. The main results are summarized in

\section{Proposition 2}

With monopolistic competition in the goods market and factor immobility, the labormarket reforms in country $A$ lead to rising real wages in country $B$, i.e. $\widehat{w}_{B}>0$. The impact on employment in country $B$ depends on the unemployment compensation system in that country. If benefits are earnings-related, employment remains unchanged, i.e. $\widehat{N}_{B}=0$. If benefits are paid as flat-rate transfers, employment will increase, i.e. $\widehat{N}_{B}>0$. In country $A$ real wages decline and employment increases, i.e. $\widehat{w}_{A}<0$ and $\widehat{N}_{A}>0$.

Proof. See Appendix.

The intuition for these results is as follows: The labor market reforms in country A lead to an increase in country A's production and therefore also to a rise in world real income. As a consequence, in country B marginal revenue with respect to employment rises. The resulting increase in labor demand leads to rising real wages. The employment consequences in country B depend on the unemployment compensation system. If unemployment benefits are earnings-related, employment is determined by the wage-setting equation $\left(20^{\prime}\right)$ alone, which is only influenced by domestic variables. As a result, employment in country $\mathrm{B}$ is not affected by the reforms undertaken abroad. ${ }^{13}$ In this case the aggregate income effect leads to rising real wages until the equality of marginal revenue and real wages is restored at the initial employment level. With flat-rate benefits the wage-setting curve is upward sloping in real wage-employment space. The shift of the labor demand curve then not only increases real wages but also employment in country B. In the latter case there are two effects working in opposite direction in country A. The

\footnotetext{
${ }^{13}$ It might be suspected that this result is only obtained with a Cobb-Douglas production function (in combination with earnings-related benefits). For instance, with a CES function the wage-setting curve is no longer vertical but upward-sloping in $w_{j}-N_{j}$ space (if the elasticity between labor and capital is less than one). However, Beissinger, Büsse (2000) have shown that even in this case the result of unchanged employment is obtained. The reason is that the wage-setting curve and the labor demand curve in country B are shifting by the same amount if employment in country A changes.
} 
direct impact of the labor market reforms cet. par. leads to lower real wages. However, the implied rise in employment in country B also shifts the labor demand curve in country A to the right, leading cet. par. to higher real wages. From the comparative-static results described in the appendix it follows that the repercussion effect from country B is weaker than the initial impulse in country A, which implies that real wages in country A will unambiguously decrease in response to the labor market reforms. The remaining comparative-static results are summarized in

Corollary 1 With monopolistic competition in the goods market and factor immobility, the following results hold irrespective of the unemployment compensation system: relative prices change in favor of country $A$, i.e. $\widehat{p}_{A}<0, \widehat{p}_{B}>0$ and hence $\widehat{p}_{A}-\widehat{p}_{B}<0$. Production in country $A$ and world real output increase, i.e. $\widehat{Y}_{A}>0$ and $\widehat{Y}>0$. The tax rate on wage income in country $A$ declines, i.e. $\widehat{t}_{A}<0$. If unemployment benefits are earnings-related production and taxes in country $B$ remain unchanged, i.e. $\widehat{Y}_{B}=0$ and $\widehat{t}_{B}=0$. If benefits are paid as flat-rate transfers production in country $B$ increases and the tax rate on wage income declines, i.e. $\widehat{Y}_{B}>0$ and $\widehat{t}_{B}<0$.

Proof. See Appendix.

In country B real wages (and with flat-rate benefits also employment) increase despite the rise in relative prices. Hence, it can be concluded that the favorable aggregate income effect dominates the unfavorable relative price effect. As a final remark note that in the model variant with monopolistic competition trade in goods will occur between countries. Due to the static framework the current account of each country must be balanced. If capital is immobile it follows that trade is also balanced between countries.

\subsection{Distributional consequences for country B}

Before going over to the more general model with capital mobility, the implications of the comparative-static results for country B are considered in more detail. With perfect competition in the goods market $(\kappa=1)$ and immobile labor and capital, country B is completely insulated from labor market shocks originating abroad. However, with monopolistic competition in the goods market (i.e. $0<\kappa<1$ ) the employees in country B 
are positively affected by the labor market reforms in country A. The result that (gross) real wages rise in country $B$ does not depend on the unemployment compensation system in that country. In order to guarantee a balanced government budget, the tax on wage income remains unchanged if benefits are earnings-related, whereas the tax rate is reduced if benefits are paid as flat-rate transfers. This implies that in both systems net real wages $w_{B}^{N} \equiv\left(1-t_{B}\right) w_{B}$ are rising. Since in the model earnings-related unemployment compensation depends on net wages, benefits are rising in the ERB system. Hence, also the unemployed are profiting from country A's labor market reforms. In the FRB system unemployment benefits are not affected, but in this case additionally country B's unemployment rate declines. Since net wages are higher than unemployment benefits, the persons who leave the unemployment pool are also profiting from country A's labor market reforms.

For the analysis of the distributional consequences in country B the change in (real) income $x_{B}$ stemming from capital income and profits must also be considered. It holds that $p_{B} Y_{B}=w_{B} N_{B}+x_{B}$, with $x_{B} \equiv r_{B} K_{B}+\Pi_{B} \cdot \Pi_{B}$ denotes real profits and $p_{B} Y_{B}$ country B's output in terms of the aggregate good. If this equation is written in relative changes, it follows that

$$
\widehat{p}_{B}+\widehat{Y}_{B}=\psi_{N}\left(\widehat{w}_{B}+\widehat{N}_{B}\right)+\psi_{K}\left(\widehat{r}_{B}+\widehat{K}_{B}\right)+(1-\kappa) \widehat{\Pi}_{B}
$$

where $\psi_{N} \equiv \alpha \kappa$ and $\psi_{K} \equiv(1-\alpha) \kappa$ again denote the share of wage and capital income in total income. Hence,

$$
\widehat{x}_{B}=\left(\widehat{p}_{B}+\widehat{Y}_{B}\right)-\psi_{N}\left(\widehat{w}_{B}+\widehat{N}_{B}\right) .
$$

\section{Proposition 3}

With monopolistic competition in the goods market and immobile capital, the labor market reforms in country $A$ lead to $\widehat{x}_{B}>0$, where $x_{B}$ denotes the sum of capital income and profits (in terms of the aggregate good).

Proof. If the comparative-static results for the ERB system are inserted into eq. (28), one obtains $\widehat{x}_{B}=-\left((1-\alpha \kappa) \omega_{2} / \beta\right) \Omega_{A}>0 .{ }^{14}$ With the results for the FRB system it follows that $\widehat{x}_{B}=-\omega_{2}(1-\alpha \kappa)(1+\nu \beta) \Lambda \widetilde{\Omega}_{A}>0$.

\footnotetext{
${ }^{14}$ The comparative-static results are found in the proof of Proposition 2 and Corollary 1 in the appendix.
} 
Table 1

Results for country $B$ if country $A$ undertakes employment-enhancing labor market reforms in a world with immobile capital

\begin{tabular}{|c|ccc|ccc|}
\hline & \multicolumn{5}{|c|}{ Degree of competition in the goods market } \\
& \multicolumn{3}{|c|}{$\kappa=1$} & \multicolumn{2}{c|}{$0<\kappa<1$} \\
\hline ERB & $\widehat{u}_{B}=0$ & $\widehat{w}_{B}^{N}=0$ & $\widehat{x}_{B}=0$ & $\widehat{u}_{B}=0$ & $\widehat{w}_{B}^{N}>0$ & $\widehat{x}_{B}>0$ \\
FRB & $\widehat{u}_{B}=0$ & $\widehat{w}_{B}^{N}=0$ & $\widehat{x}_{B}=0$ & $\widehat{u}_{B}<0$ & $\widehat{w}_{B}^{N}>0$ & $\widehat{x}_{B}>0$ \\
\hline
\end{tabular}

Notes: If $\kappa=1$, perfect competition prevails in the goods market. $0<\kappa<1$ describes a situation with monopolistic competition. $\widehat{u}_{B}, \widehat{w}_{B}^{N}$, and $\widehat{x}_{B}$ denote the change in the unemployment rate, net real wages and capital income (plus profits), respectively, for country B. ERB: earnings-related benefits; FRB: flat-rate benefits.

The results with respect to $\widehat{u}_{B}, \widehat{w}_{B}^{N}$ and $\widehat{x}_{B}$ are summarized in table 1 . Due to these results it must be concluded that in a world with immobile capital fears of a "race to the bottom" of welfare states are not justified. Since all types of households in country B (independent of the main income source) are either not affected or positively influenced by labor-market reforms abroad, there seems to be no need to diminish the generosity of the domestic welfare system. However, modern welfare states today have to deal with a situation where capital mobility has significantly increased. In the next section it is therefore scrutinized whether the results derived so far are also obtained when induced capital flows are taken into account.

\section{The results with mobile capital}

As in section 3 the main comparative-static results for the (simpler) case with perfect competition are derived first. A more detailed analysis which also takes account of the distributional consequences is then performed for the more general model with monopolistic competition in the goods market. 


\subsection{Perfect competition in the goods market}

Since with perfect competition in the goods market a homogenous good is produced, capital mobility now leads to factor price equalization. This can be seen by inserting the national version of the capital demand equation (8) into the national version of the labor demand equation (7) and taking into account that $\kappa=1$. It follows that real wages must be equal, i.e. $w_{A}=w_{B}$. The main consequences of the labor market reforms in country $\mathrm{A}$ are summarized in

\section{Proposition 4}

With perfect competition in the goods market and mobile capital, the labor-market reforms in country $A$ lead to a real wage decline in country $B$, which is the same size as in country $A$, i.e. $\widehat{w}_{B}=\widehat{w}_{A}=\widehat{w}$ and $\widehat{w}<0$. The impact on employment in country $B$ depends on the unemployment compensation system in that country. If benefits are earnings-related employment remains unchanged, i.e. $\widehat{N}_{B}=0$. If benefits are paid as flat-rate transfers employment will decrease, i.e. $\widehat{N}_{B}<0$. These effects are caused by the flow of capital towards country A, i.e. $\widehat{K}_{A}>0$ and $\widehat{K}_{B}<0$. The capital is attracted by an increase in the world real interest rate, i.e. $\widehat{r}>0$. Along with the real wage decline, in country A employment increases, i.e. $\widehat{N}_{A}>0$.

Proof. See Appendix.

Due to capital outflows the employees in country B are harmed by the reforms in country A, which is in contrast to all discussed model variants with immobile capital. A lower stock of capital implies a declining labor demand. If benefits are earnings-related the real wage response in country B is flexible enough to prevent changes in employment. However, the employees in country $\mathrm{B}$ are experiencing a real wage decline, which in equilibrium is the same as in country A. With flat-rate benefits the decrease in real wages in country B is only brought about by shrinking employment. Since in country A employment and capital are increasing, it follows that production in country A is rising. Due to the capital outflow (and shrinking employment in the case of flat-rate benefits) production in country $\mathrm{B}$ is decreasing. 


\subsection{Monopolistic competition in the goods market}

In this section it is scrutinized whether the results derived above also hold when there is monopolistic competition in the goods market. The impact of country A's labor market reforms on country B now depends on three effects: the relative price effect, the aggregate income effect and the effect caused by induced capital flows. Note that with heterogenous goods and different labor market institutions, real wages are not equalized between countries. From eqs. (10) and (11) it follows for $0<\kappa<1$

$$
\begin{aligned}
\widehat{N}_{j} & =-\frac{\psi_{K}}{1-\kappa} \widehat{r}-\frac{1-\psi_{K}}{1-\kappa} \widehat{w}_{j}+\widehat{Y} & j & =A, B \quad \text { and } \\
\widehat{K}_{j} & =-\frac{1-\psi_{N}}{1-\kappa} \widehat{r}-\frac{\psi_{N}}{1-\kappa} \widehat{w}_{j}+\widehat{Y} & j & =A, B .
\end{aligned}
$$

To obtain these equations, it was taken into account that $1-\psi_{N}-\psi_{K}=1-\kappa$. The main results are summarized in

\section{Proposition 5}

With monopolistic competition in the goods market and mobile capital, in country $B$ the

labor-market consequences of the reforms in country $A$ depend on whether $\kappa \gtreqless 1 /(2-\alpha)$. If $\kappa>1 /(2-\alpha)$ real wages in country $B$ decline, i.e. $\widehat{w}_{B}<0$. The impact on employment in country $B$ depends on the unemployment compensation system in that country. With earnings-related unemployment benefits employment remains unchanged, i.e. $\widehat{N}_{B}=0$. If benefits are paid as flat-rate transfers employment decreases, i.e. $\widehat{N}_{B}<0$. If $\kappa<1 /(2-\alpha)$ real wages in country $B$ increase and employment rises (with flat-rate benefits) or remains unchanged (with earnings-related benefits). In the limiting case $\kappa=1 /(2-\alpha)$ employment and real wages do not change in country $B$. With the labor market reforms country $A$ attracts capital, i.e. $\widehat{K}_{A}>0$ and $\widehat{K}_{B}<0$. The capital flows are accompanied by an increase in the world real interest rate, i.e. $\widehat{r}>0$. Furthermore, in country A real wages decline and employment increases, i.e. $\widehat{w}_{A}<0$ and $\widehat{N}_{A}>0$.

Proof: See Appendix.

According to Proposition 5 employees in country B are adversely affected by the labor market reforms in country $\mathrm{A}$, if

$$
\kappa>1 /(2-\alpha) \text { or equivalently } \eta>1+1 /(1-\alpha)
$$


Otherwise the reforms in country A will have a positive impact on employees in country B. This condition can be easily interpreted by going back to the factor demand equations (7) and (8). If $\kappa$ (and therefore $\eta$ ) increases, the aggregate income effect is reduced. At the same time the elasticities with regard to the respective factor price and the other factor input increase. The labor market reforms in country A increase employment in that country. With a high $\kappa$ the rise in labor input leads to a more pronounced rise in capital demand in country A. Furthermore, the resulting increase in interest rates causes a stronger capital outflow from country B and a more pronounced decline in labor demand in that country. At the same time a higher $\kappa$ implies a higher elasticity of the demand for goods and therefore a stronger shift of relative demand towards goods produced in country A. To put it more simply: a higher degree of competition in the goods market reduces the (favorable) aggregate income effect and increases the (unfavorable) relative price effect and the induced capital flows. As a result, it becomes more likely that country B is adversely affected.

Corollary 2 With monopolistic competition in the goods market and mobile capital, the following results hold irrespective of the unemployment compensation system: relative prices change in favor of country $A$, i.e. $\widehat{p}_{A}<0, \widehat{p}_{B}>0$ and hence $\widehat{p}_{A}-\widehat{p}_{B}<0$. Production in country $A$ and world real output increase, i.e. $\widehat{Y}_{A}>0$ and $\widehat{Y}>0$. If unemployment benefits are earnings-related output in country $B$ declines, i.e. $\widehat{Y}_{B}<0$. The tax rate on wage income remains unchanged, i.e. $\widehat{t}_{B}=0$. If benefits are paid as flat-rate transfers it holds that $\widehat{t}_{B} \gtreqless 0$ if $\kappa \gtreqless 1 /(2-\alpha)$. Furthermore, $\widehat{Y}_{B} \gtreqless 0$ if $\kappa \lesseqgtr \alpha /[1+(1-\alpha) \nu \beta]$.

Proof. See Appendix.

If in country B benefits are earnings-related, the outflow of capital leads to lower production although the employment level remains unchanged. If in country B benefits are paid as flat-rate transfers, the change in output again depends on the elasticity for the demand of goods. However, the condition for a declining output in country B is less stringent than the condition for declining real wages and employment, since the capital outflow dampens production even if employment increases. From Corollary 2 it follows that a sufficient condition for a declining production in country $\mathrm{B}$ is $\kappa>\alpha$, which is 
the same as $\eta>1 /(1-\alpha)$. Whatever the result for production in country $\mathrm{B}$, it holds that due to the labor market reforms in country A aggregate output $Y$ rises. The labor market reforms in country A lead to an inflow of capital. Since current accounts must be balanced and country B receives capital income from country A, it can be deduced without further computations that the labor market reforms in country A lead to a trade deficit in country B.

\subsection{Distributional consequences for country B}

If condition (31) holds and an ERB system prevails in country B, (gross and net) real wages will decrease but employment remains unchanged. Since unemployment benefits are a function of after-tax wages, unemployment compensaton declines as well. Hence employees and unemployed persons in country B are adversely affected. With flat-rate benefits employment shrinks and (gross and net) real wages decline (note that the income tax rate is increased if condition (31) holds). Unemployment benefits remain unchanged, but more persons now receive unemployment benefits instead of wage income.

Turning to the change in capital income and profits, it must be taken into account that capital input declines in country B. However, some capital owners of country B now supply their capital endowment to country A and receive their capital income from that country. Instead of eq. (28) the change in capital income and profits now is

$$
\widehat{x}_{B}=\left(\widehat{p}_{B}+\widehat{Y}_{B}\right)-\psi_{N}\left(\widehat{w}_{B}+\widehat{N}_{B}\right)-\psi_{K} \widehat{K}_{B}
$$

where the last term is positive since $\widehat{K}_{B}<0$.

\section{Proposition 6}

With monopolistic competition in the goods market and mobile capital, the labor market reforms in country $A$ lead to $\widehat{x}_{B}>0$. Hence, households in country $B$ whose income primarily stems from capital income and profits are always profiting from the labor market reforms in country A, even if country B's employees are adversely affected.

Proof. If the comparative-static results derived in the proofs of propostion 5 and Corol- 
lary 2 are inserted into eq. (32), one obtains for the ERB system

$$
\widehat{x}_{B}=-\frac{1-2 \kappa+\kappa^{2}(1+\alpha(1-\alpha))}{2 \beta(1-\kappa(1-\alpha))} \alpha \Omega_{A}>0
$$

and for the FRB system

$$
\widehat{x}_{B}=-\frac{\left[1-2 \kappa+\kappa^{2}(1+\alpha(1-\alpha))\right] \beta \nu+\left(1+\kappa^{2}-2 \kappa\right)}{2[(1-\kappa(1-\alpha)) \nu \beta+1-\kappa](\nu \beta+1-\alpha)} \alpha \widetilde{\Omega}_{A}>0 .
$$

Table 2

Results for country $B$ if country A undertakes employment-enhancing labor market

\begin{tabular}{|c|c|c|c|c|c|c|}
\hline \multirow[b]{2}{*}{ ERB } & \multicolumn{6}{|c|}{ Degree of competition in the goods market } \\
\hline & $\widehat{u}_{B}=0$ & $\widehat{w}_{B}^{N}>0$ & $\widehat{x}_{B}>0$ & $\widehat{u}_{B}=0$ & $\widehat{w}_{B}<0$ & $\widehat{x}_{B}>0$ \\
\hline FRB & $\widehat{u}_{B}<0$ & $\widehat{w}_{B}>0$ & $\widehat{x}_{B}>0$ & $\widehat{u}_{B}>0$ & $\widehat{w}_{B}<0$ & $\widehat{x}_{B}>0$ \\
\hline
\end{tabular}
reforms in a world with perfect capital mobility

Notes: If $\kappa=1$, perfect competition prevails in the goods market. $0<\kappa<1$ describes a situation with monopolistic competition. $\widehat{u}_{B}, \widehat{w}_{B}^{N}$, and $\widehat{x}_{B}$ denote the change in the unemployment rate, net real wages and capital income (plus profits), respectively, for country B. ERB: earnings-related benefits; FRB: flat-rate benefits.

The results with respect to $\widehat{u}_{B}, \widehat{w}_{B}$ and $\widehat{x}_{B}$ are summarized in table 2. It seems plausible to assume that $\alpha \approx 0.7$. In this case the employees in country $\mathrm{B}$ are adversely affected if $\eta \gtrsim 4.5$. It is very likely that this condition holds (remember that with perfect competition $\eta \rightarrow \infty)$. In most countries the unemployment compensation system also consists of a flat-rate component, which implies that unemployment in country B will increase. 


\section{$5 \quad$ Summary and Conclusions}

This analysis contributes to the globalization debate by examining how other countries are affected if a single country weakens labor union power or reduces the generosity of unemployment benefits. In the two-country model developed in this paper it is assumed that monopolistic competition (or as a special case perfect competition) prevails in the goods market and the labor market outcome is influenced by wage bargains taking place between firms and labor unions. Goods and capital markets are integrated, whereas labor markets are separated since it is assumed that international mobility of labor is hindered by cultural and linguistic barriers. In the model two variants of unemployment compensation systems are considered with benefits either being earnings-related or paid as flat-rate transfers. By this it was demonstrated that institutional settings matter for comparative-static outcomes.

In a first step the consequences of labor market reforms were analyzed for a world with immobile capital. In country A, where the reforms are undertaken, unemployment and real wages decline. The impact on other countries (country B) depends on the degree of competition in the goods market. With perfect competition country B is completely insulated from the consequences of country A's labor-market reforms. If goods markets are characterized by monopolistic competition two effects must be taken into account: the change in relative prices leads to a shift of relative demand towards goods produced in country A. However, the rise in world real income increases factor demand in country B and is therefore favorable for that country. It has been shown that the aggregate income effect dominates the relative price effect, resulting in rising real wages and rising capital income in country B. The employment effects in country B depend on the unemployment compensation system. With flat-rate unemployment benefits the unemployment rate declines, whereas in the case of earnings-related benefits the unemployment rate remains unchanged. Due to these results it has been concluded that other countries are not harmed by a dismantling of the welfare state abroad if capital is immobile.

Nowadays, modern welfare states have to deal with a situation where capital mobility has significantly increased. In a second step it therefore was scrutinized how the results 
have to be modified if capital is perfectly mobile. With perfect competition in the goods market the induced capital flows between countries must be taken into account, whereas with monopolistic competition three effects are provoked by the labor market reforms in country $\mathrm{A}$ : on the one hand the decline in relative prices and the increase in the real interest rate leads to a shift of relative goods demand and capital flows towards country A. On the other hand the rise in aggregate income leads to an increase in factor demand in country B. It has been shown, that the results for the employees in country B depend on whether the (adverse) relative price effect and the effect due to the induced capital flows is overcompensated by the aggregate income effect. This in turn rests on the degree of competition in the goods market. With a high degree of competition in the goods market, which due to goods market deregulation seems to be a more plausible assumption, employees in country B are adversely affected by the labor market reforms in country A. As in the case with immobile capital the spillover effects depend on the unemployment compensation system in country B. With earnings-related benefits only real wages decline, whereas with flat-rate benefits also the unemployment rate increases. In contrast to these results it has been demonstrated that the households in country B, whose income primarily stems from capital income and profits, are always profiting from the labor market reforms in country A, even if employees are negatively affected.

Due to the complexity of the analysis, this paper has confined the focus on the sign of the spillover effects provoked by country-specific labor market reforms. Based on the results of this paper, the analysis could be extended by taking account of the strategic interactions between countries. The reason is that country-specific social security policies exert a (positive or negative) externality on other countries. If country A diminishes social security transfers and product market competition and capital mobility are low, other countries will profit from such a shock. This could lead to a situation where each country postpones labor market reforms and waits for other countries first to implement such reforms. However, if product market competition and capital mobility were high and the welfare system remained unchanged in other countries, country A would profit from such a policy not only because of the rise in employment but also because the real wage decline is dampened by the capital inflow. Of course, these considerations hold for 
all countries. Since the assumption of relatively high product market competition and capital mobility seems quite realistic, the model offers a theoretical justification for the hypothesis that there could be the danger of a "race to the bottom", where each country tries to attract capital by gradually reducing the welfare state.

\section{A Appendix}

The signs for the endogenous variables refer to labor market reforms in country A which imply $\Omega_{A}<0$ or $\widetilde{\Omega}_{A}<0$ (in eqs. (20) and (21)). If the reforms are due to an increase in labor unions' preferences for employment, $\phi_{A}$, or a decrease in labor union power, $\chi_{A}$, it holds that $\widehat{\mu}_{A}>0$. If the reforms are solely based on a decrease in $\rho_{A}$ or $b_{A}$ then $\widehat{\mu}_{A}=0$. The results for $\widehat{u}_{j}$ can simply be derived from $\widehat{u}_{j}=-\beta \widehat{N}_{j}, j=A, B$. Hence, they are not enumerated in this appendix.

Proof of Proposition 2 Earnings-related benefits: $\widehat{N}_{j}$ is determined by eq. $\left(20^{\prime}\right)$ and $\widehat{w}_{j}$ is then obtained from eq. (26), $j=A, B$. This leads to

$$
\begin{array}{ll}
\widehat{N}_{A}=-(1 / \beta) \Omega_{A}>0 & \widehat{N}_{B}=0 \\
\widehat{w}_{A}=\left(\left(\omega_{1}-\omega_{2}\right) / \beta\right) \Omega_{A}<0 & \widehat{w}_{B}=-\left(\omega_{2} / \beta\right) \Omega_{A}>0,
\end{array}
$$

with $\omega_{i}$ being defined after eq. (26), $0<\omega_{i}<1$ and $0<\left(\omega_{1}-\omega_{2}\right)<1$.

Flat-rate unemployment benefits: From eq. $\left(21^{\prime}\right)$ and eq. (26) it follows that

$$
\begin{aligned}
& \widehat{N}_{A}=-\Lambda\left(\omega_{1}-\omega_{2}+\nu \beta\right) \widetilde{\Omega}_{A}>0 \quad \widehat{N}_{B}=-\Lambda \omega_{2} \widetilde{\Omega}_{A}>0 \\
& \widehat{w}_{A}=\Lambda\left[\nu \beta\left(\omega_{1}-\omega_{2}\right)+\omega_{1}(1-\alpha)\right] \widetilde{\Omega}_{A}<0 \quad \widehat{w}_{B}=-\Lambda \omega_{2} \nu \beta \widetilde{\Omega}_{A}>0, \quad \text { where } \\
& \Lambda \equiv\left[\nu^{2} \beta^{2}+2\left(\omega_{1}-\omega_{2}\right) \nu \beta+\omega_{1}\left(\omega_{1}-2 \omega_{2}\right)\right]^{-1} \\
& =\left[\nu^{2} \beta^{2}+(2-\alpha(1+\kappa)) \nu \beta+(1-\alpha \kappa)(1-\alpha)\right]^{-1}>0 .
\end{aligned}
$$

Proof of Corollary 1 Taking the results of Proposition 2 into account, one obtains:

Earnings-related unemployment benefits:

$$
\begin{array}{ll}
\widehat{Y}_{A}=-(\alpha / \beta) \Omega_{A}>0 & \widehat{Y}_{B}=0 \\
\widehat{p}_{A}=\left(\omega_{2} / \beta\right) \Omega_{A}<0 & \widehat{p}_{B}=-\widehat{p}_{A}>0 \\
\widehat{t}_{A}=[1-u(1-\rho)]^{-1}\left[\Omega_{A}+(1-u) \widehat{\rho}_{A}\right]<0 & \widehat{t}_{B}=0 \\
\widehat{Y}=-[(\alpha / 2) / \beta] \Omega_{A}>0 . &
\end{array}
$$


Flat-rate unemployment benefits:

$$
\begin{array}{ll}
\widehat{Y}_{A}=-\Lambda \alpha\left(\omega_{1}-\omega_{2}+\nu \beta\right) \widetilde{\Omega}_{A}>0 & \widehat{Y}_{B}=-\Lambda \alpha \omega_{2} \widetilde{\Omega}_{A}>0 \\
\widehat{p}_{A}=\left[\omega_{2} /\left(\nu \beta+\omega_{1}\right)\right] \widetilde{\Omega}_{A}<0 & \widehat{p}_{B}=-\widehat{p}_{A}>0 \\
\widehat{t}_{A}=\frac{\Lambda \Gamma \widetilde{\Omega}_{A}}{(1-u)}+\widehat{b}_{A}<0 & \widehat{t}_{B}=\frac{\Lambda \beta \omega_{2}[1+\nu(1-u)]}{1-u} \widetilde{\Omega}_{A}<0 \\
\widehat{Y}=-[(\alpha / 2) /(\nu \beta+1-\alpha)] \widetilde{\Omega}_{A}>0 . &
\end{array}
$$

$\Lambda>0$ is defined in the proof of Proposition 2. In the expression for $\widehat{t}_{A}, \Gamma$ is defined as

$$
\Gamma \equiv \beta\left(\omega_{1}-\omega_{2}+\nu \beta\right)-(1-u)\left[\nu \beta\left(\omega_{1}-\omega_{2}\right)+\omega_{1}(1-\alpha)\right] \text {. }
$$

Since $1-\alpha=\left(\omega_{1}-2 \omega_{2}\right)$ and since due to eq. (12), $(1-u)=\beta u, \Gamma$ can be rewritten as

$$
\Gamma=\beta^{2} \nu\left[1-u\left(\omega_{1}-\omega_{2}\right)\right]+\beta\left[\left(\omega_{1}-\omega_{2}\right)-u \omega_{1}\left(\omega_{1}-2 \omega_{2}\right)\right]
$$

Since $0<\omega_{1}-\omega_{2}<1$, the first term in brackets is positive. A positive sign also results for the second term in brackets, since $\omega_{1}-\omega_{2}>\omega_{1}-2 \omega_{2}$ and $\omega_{1}<1$. As a result, $\Gamma>0$, which leads to $\widehat{t}_{A}<0$.

Proof of Proposition 4 With $\kappa=1$ the factor demand equations (10) and (11) become:

$$
\widehat{N}_{j}=-(1 /(1-\alpha)) \widehat{w}_{j}+\widehat{K}_{j}, \quad \text { and } \quad \widehat{K}_{j}=-(1 / \alpha) \widehat{r}+\widehat{N}_{j}, \quad j=A, B .
$$

To derive the solution for $\widehat{N}_{j}, \widehat{K}_{j}, \widehat{w}_{j}$ and $\widehat{r}$, eqs. (A.1) must be combined with the capital market equilibrium condition $\left(24^{\prime}\right)$ and the respective wage-setting equations $\left(20^{\prime}\right)$ or $\left(21^{\prime}\right)$. Earnings-related unemployment benefits: According to eq. $\left(20^{\prime}\right), \widehat{N}_{A}>0$ and $\widehat{N}_{B}=0$. From the remaining equations one obtains: $\widehat{K}_{A}=-\Omega_{A} /(2 \beta)>0$ and $\widehat{K}_{B}=-\widehat{K}_{A}<0$, $\widehat{r}=-\alpha \Omega_{A} /(2 \beta)>0$ and $\widehat{w}_{A}=\widehat{w}_{B}=(1-\alpha) \Omega_{A} /(2 \beta)<0$.

Flat-rate unemployment benefits: In this case eqs. $\left(21^{\prime}\right),\left(24^{\prime}\right)$ and (A.1) must be considered simultaneously. The solutions for employment, capital and factor prices are:

$$
\begin{array}{ll}
\widehat{N}_{A}=-\frac{1-\alpha+2 \nu \beta}{(1-\alpha+\nu \beta) 2 \nu \beta} \widetilde{\Omega}_{A}>0 & \widehat{N}_{B}=\frac{1-\alpha}{(1-\alpha+\nu \beta) 2 \nu \beta} \widetilde{\Omega}_{A}<0 \\
\widehat{K}_{A}=-\frac{1}{2 \nu \beta} \widetilde{\Omega}_{A}>0 & \widehat{K}_{B}=-\widehat{K}_{A}<0 \\
\widehat{w}_{A}=\widehat{w}_{B}=\frac{1-\alpha}{2(1-\alpha+\nu \beta) \widetilde{\Omega}_{A}}<0 & \widehat{r}=-\frac{\alpha}{2(1-\alpha+\nu \beta)} \widetilde{\Omega}_{A}>0 .
\end{array}
$$

Proof of Proposition 5 The wage-setting equations $\left(20^{\prime}\right)$ or $\left(21^{\prime}\right)$ (depending on the unemployment compensation system), eq. $\left(24^{\prime}\right)$ for capital market equilibrium, eq. (25') 
for aggregate output and eqs. (29) and (30) form a subsystem of the complete model, which must be considered to determine the solution for the endogenous variables $\widehat{r}, \widehat{Y}$, $\widehat{N}_{j}, \widehat{K}_{j}$ and $\widehat{w}_{j}$ for $j=A, B$.

Earnings-related unemployment benefits: Defining $\Upsilon \equiv[2 \beta(1-\kappa(1-\alpha))]^{-1}$, one obtains:

$$
\begin{array}{rlrl}
\widehat{N}_{A} & =-(1 / \beta) \Omega_{A}>0 & \widehat{N}_{B}=0 \\
\widehat{K}_{A}=-\Upsilon \alpha \kappa \Omega_{A}>0 & \widehat{K}_{B}=-\widehat{K}_{A}<0 \\
\widehat{w}_{A}=\Upsilon[2(1-\alpha)(1-\kappa)+\alpha(1-\alpha \kappa)] \Omega_{A}<0 & & \widehat{w}_{B}=\Upsilon \alpha[\kappa(2-\alpha)-1] \Omega_{A} \gtreqless 0 \\
\widehat{r} & =-[(\alpha / 2) / \beta] \Omega_{A}>0 & &
\end{array}
$$

Flat-rate unemployment benefits: Eq. (25') is inserted into eqs. (29) and (30). Then real wages are eliminated by taking account of eq. $\left(21^{\prime}\right)$. Bearing in mind that $\widehat{K}_{A}=-\widehat{K}_{B}$, one obtains the following system of equations for $\widehat{N}_{A}, \widehat{N}_{B}$ and $\widehat{r}$ :

$$
\begin{array}{r}
{\left[2(1-\kappa)+2\left(1-\psi_{K}\right) \nu \beta-(1-\kappa) \alpha\right] \widehat{N}_{A}+2 \psi_{K} \widehat{r}-\alpha(1-\kappa) \widehat{N}_{B}+2\left(1-\psi_{K}\right) \widetilde{\Omega}_{A}=0} \\
{\left[2(1-\kappa)+2\left(1-\psi_{K}\right) \nu \beta-(1-\kappa) \alpha\right] \widehat{N}_{B}+2 \psi_{K} \widehat{r}-\alpha(1-\kappa) \widehat{N}_{A}=0} \\
2\left(1-\psi_{N}\right) \widehat{r}-\left[\alpha(1-\kappa)-\psi_{N} \nu \beta\right] \widehat{N}_{A}-\left[\alpha(1-\kappa)-\psi_{N} \nu \beta\right] \widehat{N}_{B}+\psi_{N} \widetilde{\Omega}_{A}=0
\end{array}
$$

where $\psi_{N} \equiv \alpha \kappa, \psi_{K} \equiv(1-\alpha) \kappa$ and $\widetilde{\Omega}_{A}<0$. Defining the expression $\Theta$ as $\Theta \equiv 2^{-1}\left\{[1-\kappa(1-\alpha)] \nu^{2} \beta^{2}+[(1-\alpha) \alpha \kappa+(1-\kappa)(2-\alpha)] \nu \beta+(1-\alpha)(1-\kappa)\right\}^{-1}>0$, one obtains:

$$
\begin{aligned}
\widehat{N}_{A} & =-\Theta\{[1-\kappa(1-\alpha)] 2 \nu \beta+(1-\alpha) \alpha \kappa+(1-\kappa)(2-\alpha)\} \widetilde{\Omega}_{A}>0 \\
\widehat{N}_{B} & =\Theta[\kappa(2-\alpha)-1] \alpha \widetilde{\Omega}_{A} \lessgtr 0 \\
\widehat{w}_{A} & =\Theta\{[(1-\alpha) \alpha \kappa+(1-\kappa)(2-\alpha)] \nu \beta+2(1-\alpha)(1-\kappa)\} \widetilde{\Omega}_{A}<0 \\
\widehat{w}_{B} & =\Theta[\kappa(2-\alpha)-1] \alpha \nu \beta \widetilde{\Omega}_{A} \lessgtr 0 \\
\widehat{K}_{A} & =-\frac{\alpha \kappa}{2[(1-\kappa(1-\alpha)) \nu \beta+1-\kappa]} \widetilde{\Omega}_{A}>0 \quad \\
\widehat{r} & =-\frac{\alpha}{2(\nu \beta+1-\alpha)} \widetilde{\Omega}_{A}>0
\end{aligned}
$$


Proof of Corollary 2 Taking account of the results of Proposition 5 one obtains:

Earnings-related benefits:

$$
\begin{array}{ll}
\widehat{Y}_{A}=-\Upsilon \alpha(2-\kappa(1-\alpha)) \Omega_{A}>0 & \widehat{Y}_{B}=\Upsilon(1-\alpha) \alpha \kappa \Omega_{A}<0 \\
\widehat{p}_{A}=\Upsilon \alpha(1-\kappa) \Omega_{A}<0 & \widehat{p}_{B}=-\widehat{p}_{A}>0 \\
\widehat{t}_{A}=[1-u(1-\rho)]^{-1}\left[\Omega_{A}+(1-u) \widehat{\rho}_{A}\right]<0 & \widehat{t}_{B}=0 \\
\widehat{Y}=-[(\alpha / 2) / \beta] \Omega_{A}>0 &
\end{array}
$$

Flat-rate unemployment benefits:

$$
\begin{aligned}
\widehat{Y}_{A} & =-\frac{\alpha[(2-\kappa(1-\alpha)) \nu \beta+2-\kappa-\alpha]}{2[(1-\kappa(1-\alpha)) \nu \beta+1-\kappa](\nu \beta+1-\alpha)} \widetilde{\Omega}_{A}>0 \\
\widehat{Y}_{B} & =\frac{\alpha[\kappa(1-\alpha) \nu \beta+\kappa-\alpha]}{2[(1-\kappa(1-\alpha)) \nu \beta+1-\kappa](\nu \beta+1-\alpha)} \widetilde{\Omega}_{A} \gtreqless 0 \\
\widehat{p}_{A} & =\frac{(1-\kappa) \alpha}{2[(1-\kappa(1-\alpha)) \nu \beta+1-\kappa]} \widetilde{\Omega}_{A}<0 \quad \widehat{p}_{B}=-\widehat{p}_{A}>0 \\
\widehat{t}_{A} & =(1 / 1-u) \widehat{u}_{A}+\widehat{b}_{A}-\widehat{w}_{A} \gtreqless 0 \\
\widehat{t}_{B} & =-\{\Theta \alpha \beta[\kappa(2-\alpha)-1][1+\nu(1-u)] /(1-u)\} \\
\widehat{Y} & =-\frac{\alpha}{2(\nu \beta+1-\alpha)} \widetilde{\Omega}_{A} \gtreqless 0
\end{aligned}
$$

\section{Literature}

Atkinson, A., Micklewright, J., 1991, Unemployment Compensation and Labor Market Transitions: A Critical Review, Journal of Economic Literature, 29, 1679-1727.

Beissinger, T., Büsse, O., 2000, Are Countries Profiting From Rising Wage Pressure Abroad?, University of Regensburg, mimeo.

Beissinger, T., Büsse, O., 2001, Bismarck Versus Beveridge: Which Unemployment Compensation System is More Prone to Labor Market Shocks?, forthcoming in FinanzArchiv.

Beissinger, T., Egger, H., 2000, Some Pitfalls in Dynamic Wage Bargaining Models, University of Regensburg Discussion Paper No. 343, July.

Blanchard, O.J., Kiyotaki, N., 1987, Monopolistic Competition and the Effects of Aggregate Demand, American Economic Review, 77(4), 647-666.

Corneo, G., 1995, National Wage Bargaining in an Internationally Integrated Product Market, European Journal of Political Economy, 11, 503-520.

Dixit, A., Stiglitz, J., 1977, Monopolistic Competition and Optimum Product Diversity, American Economic Review, 67, 297-308.

Grout, P., 1984, Investment and Wages in the Absence of Binding Contracts: A Nash Bargaining Approach, Econometrica, 52, 449-460. 
Hoel, M., 1990, Local versus Central Wage Bargaining with Endogenous Investments, Scandinavian Journal of Economics, 92(3), 453-469.

Krueger, A.B., 2000, From Bismarck to Maastricht: The March to European Union and the Labor Compact, Labor Economics, 7, 117-134.

Layard, R., Nickell, S., Jackman, R., 1991, Unemployment, Oxford: Oxford University Press.

Lejour, A.M., Verbon, A.A., 1996, Capital Mobility, Wage Bargaining, and Social Insurance Policies in an Economic Union, International Tax and Public Finance, 3, $495-514$.

Manning, A., 1991, The Determinants of Wage Pressure: Some Implications of a Dynamic Model, Economica, 58, 325-340.

Manning, A., 1995, Developments in Labour Market Theory and Their Implications for Macroeconomic Policy, Scottish Journal of Political Economy, 42(3), 250-266.

Michaelis, J., 1998, Zur Ökonomie von Entlohnungssystemen, Mohr, Siebeck: Tübingen.

Mishra, R., 1999, Globalization and the Welfare State, Cheltenham and Northampton: Edward Elgar.

Naylor, R., 1998, International Trade and Economic Integration when Labour Markets are Generally Unionised, European Economic Review, 42, 1251-1267.

Obstfeld, M., 1998, The Global Capital Market: Benefactor or Menace? Journal of Economic Perspectives, 12(4), 9-30.

Oswald, A.J., 1985, The Economic Theory of Trade Unions: An Introductory Survey, Scandinavian Journal of Economics, 87(2), 160-193.

Pemberton, J., 1999, Social Security: National Policies With International Implications, Economic Journal, 109, 492-508.

Rodrik, D., 1997, Has Globalization Gone Too Far? Institute for International Economics, Washington, DC.

Sinn, H.-W., 1998, European integration and the future of the welfare state, Swedish Economic Policy Review, 5, 113-132.

van der Ploeg, F., 1987, Trade Unions, Investment, and Employment, European Economic Review, 31, 1465-1492. 


\section{IZA Discussion Papers}

No. Author(s)

376

377

378

379

380

R. Fahr

P. Teixeira

L. Goerke

D. Blau

E. Tekin

J. Wagner

C. Schnabel

A. Kölling

C. Grund

D. Sliwka

L. Farrell

H. Egger
Title

Area

Date

Work and Television

5

10/01

Intergenerational Progress of Mexican-Origin

1

10/01

Workers in the U.S. Labor Market

The Promise of Workplace Training for Non-

College-Bound Youth: Theory and Evidence

from German Apprenticeship

H. Antecol

D. A. Cobb-Clark

The Sexual Harassment of Female Active-Duty

Personnel: Effects on Job Satisfaction and Intentions to Remain in the Military

A Kaldor Matching Model of Real Wage

7

Declines

The Economics of Employment Protection

D. Acemoglu

J.-S. Pischke
A. Ichino
R. T. Riphahn

M. A. Shields

T. Beissinger

T. Beissinger
Tax Evasion in a Unionised Economy

The Determinants and Consequences of Child

Care Subsidies for Single Mothers

Minimum Wages and On-the-Job Training

The Effect of Employment Protection on Worker

Effort: A Comparison of Absenteeism During and After Probation

Threshold Values in German Labor Law and Job

Dynamics in Small Firms: The Case of the

Disability Law

The Impact of Wage Increases on Job

Satisfaction - Empirical Evidence and

Theoretical Implications

Child Expenditure: The Role of Working

Mothers, Lone Parents, Sibling Composition and

Household Provision

Dynamic Wage Bargaining if Benefits are Tied to Individual Wages

The Impact of Labor Market Reforms on Capital Flows, Wages and Unemployment
3

3

1

$11 / 01$

3

3 